\title{
A didática aplicada no ensino de (Língua Estrangeira) no contexto das unidades fraseológicas para a aprendizagem.
}

(The didactics applied in the teaching of (Foreign Language) in the context of the phraseological units for learning.)

\author{
Marcos Vinicius Freitas Velloso \\ Ensino Público do Estado de Minas Gerais
}

Fecha recepción: 01-07-2018

Páginas 135-147

Fecha aceptación: 30-09-2018

\section{Resumo.}

O estudo buscou analisar a didática aplicada em atividades dentro da língua estrangeira (Espanhol) como uma proposta contextualizada de ensino das unidades fraseológicas junto aos alunos no $2^{\circ}$ ano do ensino médio de uma escola estadual de Minas Gerais. A metodologia teve desenho quase experimental, abordagem qualitativa do tipo descritiva. Para a coleta dos dados, trabalhou-se a variedade da prática aplicada, tendo como suporte a ferramenta o Google, ainda a entrevista com (teste-retest). Assim, pode-se perceber a importância de uma didática diferenciada no ensino das unidades fraseológicas para a aprendizagem de uma Língua Estrangeira a qual facilitou a incorporação de conversações e entendimento de leitores e interlocutores. Dessa forma, a didática utilizada pelo professor favoreceu de forma relevante 0 uso efetivo na prática de ensino com novos conhecimentos nas unidades fraseológicas da língua estrangeira aos alunos do $2^{\circ}$ ano do ensino médio.

Palavras-Chave: unidades; frases; textos; língua; estrangeira

\begin{abstract}
.
The study sought to analyze the didactics applied in activities within the foreign language (Spanish) as a contextualized proposal of teaching the phraseological units with the students in the second year of high school in a state school in Minas Gerais. The methodology was almost experimental design, qualitative approach of the descriptive type. For the data collection, the variety of applied practice was worked, with Google as tool support, as well as the interview with (test-retest). Thus, one can see the importance of a differentiated teaching in the teaching of the phraseological units for the learning of a Foreign Language, which facilitated the incorporation of conversations, and understanding of readers and interlocutors. Thus, the didactics used by the teacher favored in a relevant way the effective use in teaching practice with new knowledge in the phraseological units of the foreign language to the students of the second year of high school.
\end{abstract}

Keywords: units; phrases; texts; language; foreign 


\section{1.-Introdução.}

O ensino de uma língua estrangeira não é só promover a aprendizagem de regras gramaticais, mas sim aprender um conjunto de conceitos que a linguagem no contexto impõe um novo olhar, uma nova interpretação. O estudo da língua culta não implica necessariamente o estabelecimento de um critério de valor para tal variante. O que é pensado e de certa forma serve exclusivamente para determinar como é constituído para representar seu papel de maior prestígio social, que a própria sociedade the atribui.

Quando falamos de prestígio social, podemos concordar que a linguagem funciona em uma sociedade, como uma marca social de um grupo, como um elemento identificador, a semelhança acontece ao seu guarda-roupa. Estritamente falando, todas as pessoas têm uma atitude social em relação à linguagem, o que significa um julgamento de valor. Então essa atitude implica a existência de uma norma subjetiva de bem expressa que seria o ideal e hipotético educado. Ao lado, há uma realidade objetiva e conhecida, que resulta na maneira como as pessoas efetivamente praticam a linguagem na comunidade, quando precisam se comunicar oralmente ou por escrito. Isso é o que chamamos de norma objetiva, que consiste no comportamento real dos falantes nas várias situações de interação nas quais eles estão envolvidos.

Graças à importância de estudar as unidades pluriverbales no contexto de ensino e aprendizagem de línguas estrangeiras, todas as formas de ensino desde micropipetas, dicionários-deve apresentá-los e explorá-los para facilitar a incorporação da linguagem das inter alunos. Silva (2005, p. 621) confirma quando se trata dicionários de língua especificamente espanhol, o referido "qualquer trabalho lexicográfico você quer realizar ensino devem fornecer políticas adequadas dessas unidades".

Desta forma, espera-se que dicionários pedagógicos bilíngües, destinados a facilitar a busca por palavras e a compreensão do léxico da Língua Estrangeira, apresentem as expressões adequadas. A verdade é que os estudos reforçam o enriquecimento da linguagem, a linguagem não é uma má representação do fenômeno que fala, tudo 0 que ele entende e transmite individual sobre o seu mundo. Em seguida, frases jargão, provérbios, modas, etc. eles formam uma cadeia comunicativa que vai muito além da linguagem das Nações Unidas. A Identidade é completa com materiais lexicais, seu senso individual de parceiro cultural para os seus e com os outros e que correlaciona o tempo das extensões.

O contexto é seguido pelas seguintes questões: Como os alunos do segundo ano do ensino médio da escola estadual fazem uso das frases nos estudos de espanhol como língua estrangeira? 0 ensino das unidades fraseológicas pelos alunos do $2^{\circ}$ ano explica a falta de critérios para ensinar estes conteúdos? O uso de expressões coloquiais ajuda o orador o obter maior clareza e profundidade? 
O problema, é o ponto de partida de uma investigação, para González, Fernández e Camargo (2014), "significa buscar e levantar questões sobre os aspectos desconhecidos da realidade [...] para tanto, muito conhecimento e estudo é necessário, pois, se procura uma solução confiável. " Assim, o questionamento leva o problema: A falta de uma didática específica pode dificultar o processo de ensino nas aulas fraseológicas da Língua Estrangeira nos alunos do $2^{\circ}$ ano do ensino médio de uma Escola Estadual. Uma vez que os alunos fantasiam sobre o conjunto cultural para que feedback de produtos psicológicos e humanos pode ser solução muito positiva em sua carga e valor das virtudes para o seu desenvolvimento como a compreensão da diversidade pertence a eles.

Então o objetivo geral buscou: Analisar a didática como proposta de ensino nas atividades com unidades fraseológicas do espanhol como Língua Estrangeira no $2^{\circ}$ ano do ensino médio de uma escola estadual. Para Alvarenga (2013) O objetivo geral responde ao problema da pesquisa para se buscar os resultados a serem alcançados "para que" a pesquisa, González, Fernández e Camargo (2013) é como um norte do estudo, que descreve o objetivo a ser alcançado.

Já os objetivos específicos: "orientam e facilitam a tarefa no processo da investigação. Devem ser formulados de forma clara e sequencial, indicando precisamente as variáveis a serem estudadas e as atividades a serem desenvolvidas" Alvarenga (2013, p.19). Assim, procurou entender o uso de frases em estudos espanhol como língua estrangeira no segundo ano do ensino médio; Verificar o entendimento e assimilação do conteúdo da Língua Estrangeira pelos alunos do $2^{\circ}$ ano do ensino médio, encaminhar as unidades fraseológicas;

É por isso que a justificação foi feita verificando-se que o fracasso metodológico em praticar a fraseologia na ação educativa encurta a motivação, a análise do texto, depois toda a compreensão textual e a moral racional, a importância para ela. Todo 0 ensino deve permitir a mudança, pelo menos parcialmente, ou completamente entre comprada estruturalmente com um pensativo chegar ao fundo dos princípios de algo proposto, mais raciocínio, aspectos sociais e psicológicos relevantes da situação em que uma determinada questão se desenvolve.

Linguagem é algo muito dinâmico e não um número de corpo tão formal que uma ampla gama de análise é formada a partir de perspectivas de análise para estabelecer um dia para uma compreensão nas conversas do dia. É claro que as faixas etárias, isto é, os domínios diastráticos (fenômenos linguísticos relacionados ao nível de parceiro cultural dos falantes) geralmente aumentam o percentual da referida contribuição.

Quanto aos recursos expressivos do que se ele não dizer que muitos são a variedade citar: o que significa, contribuindo para as citas alegados, invasões, expressões coloquiais enriquecer os substantivos, qualidades que vão além do que eles merecem. Da mesma forma, podemos reconhecer uma certa intenção descritiva pela maneira como sabemos até onde chegam os conceitos que o autor administra. 


\section{2.-Conceito da fraseologia.}

Estas são as recentes investigações em relação à "Phraseology", apesar de ser a nova Língua para aquelas combinações estáveis usadas diariamente. Somente nos anos quarenta foram estabelecidas as bases teóricas para pesquisa na área de pesquisa do iniciador e do linguista russo Vinogradov (Santamaría, 2000). Definir 0 fim "Phraseology" é uma tarefa complexa, não há mais um conceito da ONU para esse sub-assunto de lexicologia. Alcaraz Varo e Martínez Linares (apud Montoro del Arco, 2005, p. 92) aprimoram a "fraseologia" por dois significados:

(1) O nome de 'Phraseology' é dado à disciplina cujo propósito é o estudo de unidades fraseológicas em suas várias composições. (2) 'Phraseology' também é usado para se referir ao objeto de estudo desta disciplina. Isto é, as "unidades" fraseológicas estabelecem a diversidade da comunicação. $O$ primeiro refere-se ao significado 'Phraseology' como disciplina da linha de pesquisa. E 0 segundo, estabelece o repertório do inventário de unidades fraseológicas.

Welker (2004, p.162) apresenta uma definição semelhante enfatiza como ciência que dos fraseologismos e também o conjunto de fraseologismos. Trista (. 1984, p 2002), por sua vez, opera como dois lados da "formulação". "Sentido restrito fraseologia e" fraseologia amplamente "O primeiro compreende as combinações de palavras e estruturas que têm certa...características que funcionam como elementos de frases a segunda abrange combinações com sentido restrito e combinações com indivíduo, tais como características de frases e outros são múltiplos hiperónimos para se referir "formulação" "unidade frasal", "unidade pluriverbal expressão" "lexicalizados e unidade pluriverbal habitualizada" "unidade de expressão lexical pluriverbal fixa" "fraseologia "fraseolexema" "phraseme" ou combinatória lexical". Destes, os termos mais comuns "unidade fraseológica" e fraseologia".

\section{3.-Metodologia.}

O método de pesquisa utilizado tinha a abordagem "qualitativa" após recolher os datos o qual ocorreu no âmbiente lugar natural dos participantes trabalhando as unidade de análises foi "possível perceber o falar, o agir enfim (comportamentos) dos agentes pesquisados e na sequência a tabulação para sistematizar a problemática" (Sampieri, Collado e Lucio (2008), descrevem o método de recolha de dados como um método de medição, mas num processo de interpretação para descobrir e reafirmar as questões".

O foco da pesquisa qualitativa é entender e aprofundar os fenômenos explorados a partir da perspectiva dos participantes em um ambiente natural em relação ao contexto. Gonzalez Fernandez e Camargo (2014) colocam que o método qualitativo serve para compreender um problema de caráter humano ou social, por meio da elaboração de um projeto complexo construído sobre as palavras e desenvolvido um contexto natural. 
Assim, foi possível verificar os conceitos subjetivos, que exigem certa capacidade de Intuição, percepção, para enfrentar algo com base importante dado levantamento da problemática. Contudo, exigiu-se a abertura para o campo qualitativo foi observado e a entrevista exigiu-nos um bom preparo epistemológico num olhar mais crítico sobre como concepções subjetivas de dos sujeitos investigados.

\section{1.-Tipo de investigação.}

O método de pesquisa utilizado nesta investigação foi a "quase-experimental" com abordagem "qualitativa", em seguida, recolheu-se os datos no lugar natural dos participantes na unidade análise sendo possível perceber a maneira e o modo de falar e de agir (comportamentos) apurados a partir da sistematização dos problemas levantados (Sampieri,Collado e Lucio (2008), ainda, descrevem este método para a coleta dos dados como um método se medição numérica, mas um processo de interpretação para descobrir e refinar as questões.

Assim sendo, o estudo utilizou-se de uma investigação do "tipo descritiva", "estudos descritivos, medem, avaliam e coletam datos em vários aspectos, dimenções ou componentes do fenómeno a ser investigado. Sampieri Colado e Lúcio (2008).

\section{2.-Amostra dos participantes dá a investigação.}

A investigação teve a "amostragem" não probabilística, de forma "intencional" a uma turma de 25 alunos do $2^{\circ}$ ano do ensino médio de uma escola do estado de Minas Gerais. Alvarenga (2013) coloca que a amostra intencional é quando o pesquisador decide os "casos típicos", conforme os critérios e objetivos do estudo esta amostra se dá no subgrupo numa parte da população e a eleição de dois elementos não depende de probabilidade mas, simplesmente dá características dos sujeitos da pesquisa Sampieri, Collado e Lucio (2008) Os critérios foram definidos para a classe $2^{\circ}$ ano, conforme o pesquisador fato de estar como 0 ideal para a pesquisa de "estar" entre $01^{\circ}$ e $03^{\circ}$ ano, no intuito de perceber como se dá o ensino aprendizagem dos estudantes nas unidades fraseológicas na Língua Estrangeira, tais como uma necessidade de valorizar a Língua Espanhola como linguagem de forma verbal e escrita dado 0 desenvolvimento em consideração que o ser humano é baseado no aprendizado que perturbada e leva à produção deste estudo.

\section{3.-Técnica e instrumentos para coleta dos dados.}

O primeiro contato que tivemos foi com a direção da escola para falar sobre o relato da pesquisa, onde foi explicado a importância da pesquisa, entregue a solicitação formal de permissão para a aplicação da prática pedagógica aos alunos, a qual ocorreu durante 0 mês de agosto, a entrevista aplicada um recorte de (03) questões para que os alunos pudessem responder com mais propriedade sobre a didática aplicada.

As ferramentas utilizadas na intervenção didática, coleta e análise da Expressão de 
Idiomatismo no texto foram utilizadas como ferramenta de ensino com o uso do Google. Foi efetivo, mais precisamente, no período de dois meses no ano 2017.

A investigação e a frequência dos idiomatismos foram realizadas durante 20 (vinte) dias, dado a impossibilidade de realização deste trabalho em um único dia. Como mencionamos na introdução, as ferramentas utilizadas na pesquisa foram: 0 sistema de pesquisa do Google (18) O corpus eletrônico (19) de textos peridísticos da língua espanhola e portuguesa (variante do Brasil).

\section{4.-Instrumento para coletar os dados.}

Para a análise dos resultados utilizou-se um corte do domínio de domínio com a resposta final (teste-Reteste) da entrevista dos alunos do $2^{\circ}$ ano de um Colégio de Minas Gerais. Assim, uma categoria foi separada de acordo com os objetivos, para entender como 0 uso das expressões nos estudos da Língua Espanhola como Língua Estrangeira foi deificado. Para a pesquisa das unidades fraseológicas, utilizou-se a didática com a ferramenta do "Google" para isso, buscou-se uma seleção da Expressão Idiomática nos textos. Para Alvarenga (2013) esses documentos são materiais informativos que foram gerados independentemente dos objetivos da pesquisa, são registros de eventos recentes ou passados, apenas fonte original.

As expressões idiomática no texto, selecionada no estudo foram:

$1=$ Andar/ ir de boca em boca;

2 = Andra/ vá em todos os lábios;

3 = aquece/ quebra a cabeça;

4 = Não tendo nem pés nem cabeça.

A partir da coleta dessas Expressões de Idiomatismo nos textos, também analisou-se os respectivos atrasos. Optou-se pela seleção da Expressão de Idiomatismo nos textos arrima após ter observado a abundância no DiBU dos fraseologismos nos verbos com partes do corpo. Inicialmente, queríamos analisar todas as frases nos verbos com partes do corpo, mas, nem todas eram idiomáticas. Assim, decidimos selecionar três fraseologias idiomáticas inseridas nos verbos "boca", três inseridas em "mão", duas inseridas em "cabeça" e duas inseridas em "pé".

\section{4.-Discussão dos resultados.}

Após a coleta dos dados na intervenção pedagógica houve a investigação no Google e junto ao "teste-Reteste" na sequência foram agrupados em categorias de acordo com os objetivos específicos: Material das unidades fraseológicas agrupados sob as variáveis de pesquisa à qual procurou-se analisar numa didática aplicada em sala de aula. Assim, fez-se o critério de análise da representatividade das expressão idiomáticas nos textos. Inicialmente observou-se o Emprego Idiomático abordado se apresentam uma frequência que justifica a inclusão no DiBU22. Com base nessa observação, analisou-se ainda a maneira como eles foram inseridos, isto é, se as 
variantes usuais foram contempladas. Isso porque defende-se que os dicionários de uso não devem apenas inserir Expressões Idiomáticas, mas oferecer aos consultores as formas mais habituais no uso. A frequência dos idiomas em espanhol foram coletados no google com a frequência em português, no www.google.com.br. Para tanto, investigou-se o "idiomatisis" com os verbos no infinitivo e na terceira pessoa do presente, pretérito perfeito simples e imperfeito do indicativo. Escolheu-se a terceira pessoa porque é mais provável encontrar uma abundância de casos dessa maneira na internet, como encontramos nas coleções anteriores.

Tomámos como exemplo a Expressão Ideomática "andar/ ir de boca em boca", as ocorrências de "andar de boca em boca", "andar de boca em boca", "andar de boca em boca" e "passear boca". Posteriormente, analisou-se a frequência de "variantes' em espanhol, como "ir de boca em boca" e "correr de boca em boca". Além disso, coletou-se a frequência da Expressão Ideomática inserida como uma tradução "caminhada boca a boca" e suas possíveis variantes "estar na boca do povo". Após a coleta, analisou-se os exemplos dos corpus e algumas páginas do Google, a fim de observar em quais contextos as Expressões Idiomáticas são utilizados e mais usuais.

\section{1.-A variação da expressão idiomática.}

Caminhar/ir de boca em boca; Andar/estar na boca de todos:

DIBU visto que sugere a possibilidade verbal expressão de variação do Idiomatismo efectivou-se uma investigação no Google na tentativa de detectar o número de ocorrências de "walk-a-boca" e "boca a boca vai" Além disso, foi investigada a expressão com verbos não Idiomatismo sugerido no DIBU (corrida, sendo e passar), mas no Google existente, sem o verbo correspondente (apenas o "boca a boca" fragmento).

Eles foram detectados:

330.000 ocorrências para "boca a boca";

Em relação às ocorrências com a adição de verbos, foram encontrados:

39.182 casos.

Assim, a Expressão de Idiomatismo pode ser considerada de uso frequente na língua espanhola, o que justifica a inclusão no DiBU. Apesar por considerar a inclusão positiva da expressão "andar/de boca" em DIBU, sugerimos a inclusão do verbo "pass" com a expressão, uma vez que os dados indicam a prevalência de ocorrências para esse verbo . Isto é devido ao fato de que Expressões Idiomáticas, em essência, dá a idéia de deslocamento, algo que é transmitido de uma pessoa para a outra, então é comum o uso de verbos de movimento.

Outros verbos que indicam movimento, "ir", "correr" e "andar" obtiveram, respectivamente, a segunda, a quarta e a última posição. "Estar", por sua vez, ficou na terceira posição. Diferentemente dos outros, é um verbo de ligação com uma indicação implícita de movimento. Em algumas ocorrências, como em "Esta notícia está sendo executada de boca em boca na Internet", o verbo "ser" foi inserido por um 
verbo de movimento, formando uma frase verbal. No entanto, em outros não. A parte "a verdade é que agora é de boca em boca" é um exemplo do uso do verbo "estar" com a omissão de um verbo de movimento.

Avaliando os dados acima, percebeu-se que a Expressão Idiomática em questão poderia ter sido apresentada no dicionário de forma mais curiosa, pois além de não ter sido inserido o verbo "passar", indicado em nossas investigações como o mais usual, no exemplo que acompanha a expressão (o escândalo do prefeito decorre de boca em boca) não inclui nenhum dos dois verbos incluídos no DiBU. Devido aos limites de espaço para os fraseologismos neste tipo de dicionário, é compreensível que o verbo "correr" não tenha sido envolvido, uma vez que não é possível apresentar uma lista de possíveis variantes, mas sim selecionar as mais usuais. 0 ponto é que, se o verbo não foi inserido, ele não deveria ter sido usado no exemplo. $\mathrm{Na}$ investigação ao Expressões Idiomatismo "caminhar/ir na boca de todos" elaborouse uma tabela cujos verbos selecionados eram também "andar", "ir", "ser", "correr" e "acontecer".

\section{2.-As ocorrências predominam com o verbo "estar", ou seja:}

92.277 ocorrências com verbos,

88.304 foram de "estar".

O segundo verbo em número de ocorrências foi "andar", com:

2,818. "correr", por sua vez, apresentado

1.149 casos,

"Ir" 6 e para "passar" nenhum caso foi detectado.

Conclui-se, então, que a Expressão Idiomática apresentou um número expressivo de ocorrências, chegando a aparecer no Google 211.000 páginas, quando apenas 0 fragmento foi investigado "na boca de todos". No entanto, não foi apresentado no DiBU com o verbo "estar', verbo que obteve o maior número de ocorrências. Portanto, pode-se dizer que a expressão em causa reflete parcialmente o uso real, uma vez que tem um número considerável de ocorrências, mas aponta única verbos "caminhada" e "ir" como uma possibilidade de variação, desconsiderando o verbo "ser"

Como uma maneira de identificar a variação alternativa da expressão idiomática "caminhada/ir na boca de todos" foram investigados fragmentos "na boca do povo", "a conversa do mundo" e "em bocas de pessoas". A busca foi feita inicialmente sem a inserção de verbos e, posteriormente, com os verbos "andar", "ir", "estar", "correr" e "passar"e seguiu o modelo das duas pesquisas anteriores.

Analisou-se ainda as tabelas ocorrências, percebemos a predominância de "a conversa do mundo" sobre as outras variantes da expressão idiomática, tanto para investigar apenas fragmentos sem verbos como, além de procurá-los. 
Além disso, nas três supostas variantes havia uma preponderância do verbo "estar" e nenhuma ocorrência para o verbo "pasar". No caso do verbo "caminhar", o maior número de ocorrências foi detectado na variante "na boca do mundo inteiro" (264). Quanto ao verbo "ir", no Google estavam localizadas apenas (02) ocorrências de "na boca do mundo inteiro" e uma de "na boca do povo".

Em suma, foi possível detectar que "boca" todos é, nas últimas três variantes investigadas, o mais comum na língua espanhola, porém não mais do que o uso do Ideomatismos "na boca de todos", ou seja, o formulário apresentado no dicionário como uma segunda opção. Após a investigação análise de ocorrências, conclui-se que a inserção do "boca a boca" Idiomatismos e "na boca de todos" no DIBU foi uma opção conveniente, uma vez que os dados mostram que são comuns na língua espanhola. Recomendou-se, no entanto, a inclusão do verbo "passar" junto com a expressão "boca a boca" e "ser" junto com a variante "nos lábios de todos". No que diz respeito à tradução, no DiBU existem as Expressões Idiomáticas "andando de boca em boca" e "caindo/estando na boca do povo".

Em relação à frequência do Google:

"Boca a boca" apresentou 52.100 ocorrências;

"Ande de boca em boca", 1.328;

"Circular de boca a boca", 268;

"Correndo de boca em boca", 1,623;

"Dispersão de boca a boca", 15;

"Vá de boca em boca", 1.545,

"Passe de boca em boca", 1,631,

"Transmitir de boca em boca", 9.

Em resumo, o fragmento de "boca em boca" apresentou mais de 50.000 ocorrências. E na busca para a expressão idiomática incluindo verbos, ele dominou 0 verbo "ir" em seguanda posição do verbo "correr" terceiro o verbo "ir" e somente no quarto do verbo "andar" verbo sugerido em o DiBU. "Circular', "espalhar" e "transmitir" foram os verbos com o menor número de ocorrências. Dado que "de boca a boca" tem frequência expressiva, sua inserção no DiBU é válida, porém os dados coletados indicam que "ir de boca a boca" e "correr de boca a boca" podem ser incluídos como outras opções de variação. .

Na busca por "na boca do povo" foram verificadas 7.257 ocorrências que foram investigadas incluindo os verbos. Os verbos "cair" e "ser" predominam, evidenciando que a Expressão Idiomática, como foi apresentada no DiBU, é usual na língua portuguesa. Como exemplo da investigação da Expressão Ideomática em espanhol, outras possibilidades de variação de "na boca do povo" foram investigadas: "na boca de todos" e "na boca do mundo inteiro".

4.3.-Datas da variação da Expressão Idiomática.

Pela primeira variante "foram detectados em 10.900 ocorrências sem verbos 
Um total de 6.782 verbos" "andar", "cair", "circular", "correr" e "estar" o que prevaleceu foi estar na boca tudo.

Em "na boca do mundo todo" ocorreram 4.900 ocorrências sem inserção de verbos 1.691 ocorrências com os mesmos verbos investigados na primeira variação. Mais uma vez prevaleceu a variação com o verbo "estar". Em suma, "na boca" tem ocorrências mínimas, se comparado com os resultados de "na boca de todos" e "na boca do povo". Isso mostra a representatividade do maior uso real de "na boca do povo", bem como detectar a relevância do verbo "estar".

Desse modo, justificou-se a opção dos idiomatismos, descritos nas ferramentas utilizadas e os critérios formulados para a análise da representatividade, que foram: Expressões Idiomatismos representativos quando a variante inserida no DiBU era a mais usual; Expressões Idiomatismos parcialmente representativas quando detectado um menor número de ocorrências na forma como foi inserido no DiBU e superior quando investigado com outras variantes; Expressões Idiomatismos com representação nula quando nenhuma ocorrência foi localizada no Google, nem no corpus de expressão idiomática. Visto que não é possível determinar a extensão do Google ou o número mínimo de ocorrências que deve haver uma expressão de Idiomatismo para ser considerada representativa, na elaboração dos critérios partimos do pressuposto de que, se uma única palavra pode ser considerado altamente representativo quando aparece 10.000 vezes no Google, para um idiomático constituído de três palavras, seja em espanhol ou português, podemos considerar 10 ocorrências como um número significativo.

\section{4.-Entrevistas.}

a).- Sobre a didática nas Unidades das Frases da Língua Estrangeira.

Primeiro teste:

Dos 25 alunos do $2^{\circ}$ ano do Ensino Fundamental (18) disseram que não conseguiam entender nada ou quase nada sobre as unidades fraseológicas atribuíram à falta de explicação. Outros (07) disseram que entendiam um pouco, mas tinham muitas dúvidas sobre as Unidades de Frases do Espanhol como Língua Estrangeira, por não entenderem o processo dentro da aprendizagem.

Reteste:

A1, A2, A3, A4: Agora consigo entender melhor com as explicações do professor ou as outras formas de esclarecimentos mais elevados tudo melhorou aprendi a gostar da língua estrangeira; A5, A6, A7, A8: Quando o professor explica ou passa exemplos, partindo de uma explicação mais objetiva tudo fica mais fácil; $A 9, A 10$, A11, A12, A13, A14, A15: Agora eu já consigo entender mais e melhor, ainda assim é um pouco difícil pra mim assimilar as Unidades Fraseológicas e as Expressões Idiomática da língua estrangeira; A16, A17, A18: Eu entendo bem melhor agora, 0 professor costuma explicar, no quadro, dá exemplos orais e escritos a gente pesquisa no Google, faz trabalho em grupo ai fica mais fácil a gente pode comparar, ver o significados e outros e exemplos; A19, A20, A21: Eu entendo mais com as explicações do professor nas conversas debates e exemplos que ele passa pra tirar 
minhas dúvidas; A22, A23, A24, A25: Eu prefiro as explicações esclarecedoras do professor consigo entender melhor.

b).-Sobre ou meta do Língua Estrangeira.

Teste:

Dois 25 anos do $2^{\circ}$ ano do meio (20) não conseguiram dizer qual seria o objetivo de uma língua estrangeira como uma disciplina estrangeira até disseram que seria desnecessária. (05) disseram que é interessante entender as pessoas de outros países, porque neste caso tinham amigos estrangeiros.

\section{Reteste:}

A1, A2: Mostrar que há coisas...muito mais para conhecer, mas de um jeito diferente; A3, A4: As unidades fraseológicas são utilizadas como o de a gente entender melhor a língua falada; $A 5, A 6, A 7$ : Para entender melhor, poder praticar a conversação com os estrangeiros; A8, A9, A10, A11: Para poder se comunicar melhor com pessoas de outras nacionalidades, mas também para compreender os filmes, jogos e outros; A12, A13, A14: O objetivo é poder entender melhor a língua espanhola ou "Español"; A15, A16, A17: Comparar a minha própria língua e poder aprender novas formas de falar sobre algo de forma normal é muito interessante; A18, A19, A20: 0 objetivo ajudar para que possamos nos comunicar com outras pessoas de outros países; A21, A22, A23, A24, A25: O objetivo é nos mostrar coisas que a gente já conhece mas de nome e jeito diferente.

\section{c).-A contribuição da didática para o ensino da Língua Estrangeira.}

Teste:

Dos 25 alunos do $2^{\circ}$ ano do ensino médio (20) os alunos não entenderam o que significa didática do ensino, apenas apontaram que os professores não explicaram 0 que não entendiam. (05) Eles disseram que os professores repetiam as mesmas atividades práticas e leituras com pouca explicação

Reteste:

A1, A2, A3, 15: A forma diferenciada do professor dar sua aula contribuiu muito e de várias maneiras, assim vamos tendo 0 entendimento de forma mais dinâmica e fácil da língua estrangeira; $A 5, A 6, A 7, A 8, A 9 A 10, A 11, A 12, A 13, A 14$ : A didática facilita muito a matéria, tira dúvidas, diminui as dificuldades, melhora 0 entendimento; $A 2$, A16: Contribui muito para eu entender melhor e no futuro que sabe poder visitar países falando uma língua estrangeira: A17, A18: Contribui porque facilita a aprendizagem e o entendimento e que eu melhore cada vez mais o uso da língua espanhola; A19, A20: A didática utilizada me ajuda muito até na minha vida "Amizade" tenho uma amiga que mora fora do Brasil e agora consigo entender e me comunicar melhor com ela. A21, A22: Com certeza as diferentes formas de ensinar ajuda naquilo que a gente já conhece a ir a um nível maior de entendimento da Língua estrangeira; A23, A24, A25: Eu posso dizer que aprendi muito... o professor da aula diferenciada assim facilita pra gente aprender a matéria, palavras depois frases passada na lousa, traduzidas depois pesquisadas no Google, trabalhos em grupo, letras de músicas, vídeos e ao final exposição seminários. 


\section{5.-Conclusão.}

Ao falar de uma língua estrangeira falamos de um grande prestígio social, no entanto, a linguagem funciona em uma sociedade, como marca social de um grupo, como um elemento identificador podendo ser comparada a imagem do seu guardaroupa, algo único. Estritamente falando, todas as pessoas têm uma atitude social em relação à linguagem, o que significa um juízo de valor.

Observou-se ainda que na atitude dos estudantes implica a existência de uma norma subjetiva que bem expressa que seria o ideal de cada um. Além disso, existe uma realidade objetiva e conhecida, resultante da maneira como as pessoas realmente praticam a linguagem em comunidade, quando precisam se comunicar oralmente ou por escrito.

A didática utilizada pelo professor favoreceu de forma relevante o uso efetivo na prática das unidades fraseológicas junto aos alunos do $2^{\circ}$ ano do ensino médio, uma vez que a fraseologia pode ser abordada como sentido restrito, bem como, fraseologia ampliada, sendo que a primeira compreende combinações de palavras e estruturas que possuem certas características que funcionam como elementos da frase. A segunda abrange combinações com sentido e combinações restritas.

No entanto, verificou-se a importância do uso de uma didática específica para 0 desenvolvimento da fraseologia na ação educativa, motivada, por análises de forma contextualizada. Pode-se dizer que o ensino deve permitir, uma comutação parcial ou total entre 0 estrutural adquirido, com alcance reflexivo no âmbito dos aspectos sociais linguísticos mais relevantes em que uma determinada questão se desenvolve.

Enfim, a linguagem deve ser dinâmica contudo, necessária, não como um número formal, mas com um sentido amplo como uma âncora formada a partir de perspectivas para estabelecer no cotidiano uma melhor compreensão das conversas estabelecidas entre os mais variados indivíduos na interação com outros continentes.

\section{6.-Referências.}

Alvarenga, E.M. (2013). Metodologia de la Investigación Cuantitativa y cualitativa; Normas técnicas de presentación de trabajos científicos. 5a. ed. Asunción: Diseños.

González, J.A.T., Fernández, A.H., Camargo, C. de B. (2013). Aspectos Fundamentais da Pesquisa cientifica. Granada: Ediciones ADEO.

Sampieri, R.H., Collado, C.F., Lucio, P.B. (2008). Metodologia de pesquisa. 4a . ed. México: Mcgraw-hill.

Santamaría, P.I. (2000). Tratamiento de las unidades fraseológicas en la lexicografía bilingüe Español catalán. Tese de doutorado. Faculdade de Filosofia e 
Letras. Universidade de Alicante. Recuperado de: http://www.cervantesvirtual.com/FichaObra

Silva, M.Z. (2005). Notas sobre las variantes fraseológicas. Anuario de Lengua y Literatura de la Academia de Ciencias de Cuba. Cuba: Academia de Ciencias.

Welker, H.A. (2002). A apresentação de fraseologismos num dicionário alemãoportuguês de verbos (e em seis outros dicionários). (2006). Recuperado de: http://www.unb.br/il/let/welker/fraseo.doc 